\title{
Recepções da Antiguidade e usos do passado: estabelecimento dos campos e sua presença na realidade brasileira
} Receptions of Antiquity and Uses of the Past: The Establishment of Distinct Fields and Their Presence in the Brazilian Context

\author{
Glaydson José da Silva* \\ Pedro Paulo Funari** \\ Renata Senna Garraffoni***
}

\section{Resumo}

$\mathrm{O}$ artigo discute a reutilização do passado antigo em tempos posteriores, característica definidora de diferentes culturas e épocas. Para entender esses processos de reutilização, dois termos são usados com frequência: "recepção" e "usos do passado". Em diálogo com a produção internacional na área, os estudos brasileiros sobre recepção e usos do passado têm se desenvolvido de forma notável, particularmente com o aporte de formadores como Francisco Murari Pires, Pedro Paulo Abreu Funari e José Antônio Dabdab Trabulsi. A constituição e o estabelecimento desses campos têm se dado, sobremaneira, no âmbito do Grupo de Trabalho em História Antiga da Associação Nacional de História (GTHA-Anpuh), manifestando-se em diferentes publicações de au-

\begin{abstract}
The aim of this paper is to discuss the presence of Antiquity in subsequent periods as a defining feature of cultures and epochs. Two concepts are often used in the attempt to grasp such reuseprocesses: 'reception' and 'uses of the past'. In consistent dialogue with the international literature in the field, Brazilian studies on the reception and uses of the past have evolved in significant ways, particularly with the contributions of leading scholars such as Francisco Murari Pires, Pedro Paulo Abreu Funari, and José Antônio Dabdab Trabulsi. These fields emerged and were established primarily within the Working Group on Ancient History of the National Association of Historians (GTHA-Anpuh), to express themselves through national and international pub-
\end{abstract}

\footnotetext{
* Universidade Federal de São Paulo (Unifesp), Guarulhos, SP, Brasil. sglaydson@hotmail.com <https:// orcid.org/0000-0002-2229-6071>

** Universidade Estadual de Campinas (Unicamp), Campinas, SP, Brasil. ppfunari@uol.com.br <https:// orcid.org/0000-0003-0183-7622>

*** Universidade Federal do Paraná (UFPR), Curitiba, PR, Brasil. resenna93@gmail.com <https://orcid. org/0000-0002-4745-8161>
} 
tores brasileiros no Brasil e no exterior. Para além da análise dessa dinâmica nos estudos de História Antiga e das definições, aproximações e distanciamentos entre recepção e usos do passado, o presente artigo também contempla a análise específica do caso de Curitiba e a presença da Antiguidade greco-romana na cidade, como exemplo na história brasileira.

Palavras-chave: recepções da Antiguidade; usos do passado; Curitiba. lications of Brazilian authors. In addition to its analysis of this process in studies on Ancient History and distinct definitions, approaches and dissociations between forms of reception and uses of the past, this article sheds light on one brief case study regarding the city of Curitiba as an example of long term presence of Greek and Roman culture in Brazilian History.

Keywords: receptions of Antiquity; uses of the past; Curitiba.

O presente artigo visa discutir a reutilização do passado concernente à Antiguidade Clássica em contextos posteriores, característica definidora de diferentes culturas e épocas. Na história ocidental, de forma mais sistemática, isso tem início com os romanos, ${ }^{1}$ que tomaram os gregos como fonte para a literatura e as artes, a medicina, a arquitetura, a mitologia etc. Graecia capta ferum victorem cepit et artes / Intulit agresti Latio, como disse Horácio (Epístola, Il, 1, 156/7): “a Grécia conquistada conquistou a seu feroz conquistador e introduziu as artes no agreste Lácio”. Portanto, a expressão “cultura greco-romana" expressa bem essa simbiose, como atesta, entre muitos outros, Paul Veyne (2005). O cristianismo seguiu essa tradição, como atestava já todo o Novo Testamento, calcado na cultura grega. Foi o Renascimento a consolidar e desenvolver essa relação com gregos e latinos, em especial pelo estudo direto dos originais, e, desde então, esse processo não cessou.

Para entender essas apropriações classicistas têm sido usados, com frequência, dois termos: recepção e usos do passado (Hardwick; Stray, 2008; Silva et al., 2017). Recepção chama a atenção para a transmissão de algo dos produtores para os receptores, em uma metáfora da teoria da comunicação: recepção do som, de imagem, de informações. Há, pois, uma ênfase na emissão, e isso explica toda a atenção com a recuperação ou reconstrução dos textos e monumentos originais. Isso já estava presente na preocupação dos humanistas modernos que buscavam retirar das cópias manuscritas medievais a lição mais próxima daquela ditada ou escrita pelos autores. Recepção aponta para a verificação da distância entre a gênese e a recriação posterior; já os usos do passado enfatizam os contextos posteriores. Assim, cada momento usa o passado para sua própria época, seus interesses e circunstâncias. O caso da Doação de 
Constantino é um exemplo clássico: original medieval atribuído a um imperador romano, utilizado no Renascimento na luta política daquela época. Desde então, tem havido muitos usos da doação, em tempos e circunstâncias concretas posteriores. Moses Finley (1975), por exemplo, tratou dos usos e abusos da História, assim como Arnaldo Momigliano (1990); ambos trataram em detalhe dos gregos clássicos e helenísticos e suas releituras. Assim, recepção e usos do passado estão envolvidos em dois aspectos essenciais: a emissão e a recepção dos antigos em sucessivos momentos da história, de Roma ao Novo Mundo (Hingley, 2001).

Entendemos os usos do passado como uma forma de recepção entre outras possíveis, na qual a mobilização/reutilização do passado assume um caráter pragmático e instrumental, tal como aquela levada a termo durante a Revolução Francesa (Dabdab Trabulsi, 1998a), os diferentes nacionalismos (Geary, 2008) ou pelo nazifascismo (Silva, 2007, p. 25-55; Silva, 2018). Klas-Göran Karlsson (2011) aponta para os usos do passado em caráter científico-acadêmico, existencial, moral, ideológico e político pedagógico como um processo sempre mediado pela cultura. Nesse domínio, o foco reside no significado do uso do passado, naquilo que lhe é acrescido ou suprimido objetivando conferir sentido a uma finalidade (identitária, nacional, de classe, racial, de gênero etc.) no presente, entendida como uma "apropriação indevida" (Fleming, 2006), abuso. Com esse fim, os usos do passado atuam para criação e consumo de uma narrativa que, produzida no presente, não deixa de estabelecer expectativas para o futuro.

No ambiente historiográfico, tanto os estudos sobre os usos do passado quanto aqueles da recepção têm se beneficiado das análises de François Hartog, como um articulador de temporalidades a evidenciar a dimensão do presente como o ponto a partir do qual se dá a percepção, a análise e a escrita histórica sobre o passado (Hartog, 2005; Hartog; Revel, 2001). Em uma abordagem que compreende o retorno ao antigo como fortemente informado pelo presente e que trata dos usos e apropriações do passado no presente, Hartog torna indissociáveis a história e a historiografia, rompendo com a ideia de que o mundo antigo nos chega tal como uma herança, secularmente intacta, nunca afetada pelas dimensões do tempo.

Se o conceito de usos do passado tem uma perspectiva mais instrumental e específica, recepção tem um sentido mais amplo. Para Charles Martindale, a recepção dos clássicos é a materialização de um diálogo entre presente e passado em uma perspectiva bidirecional, para trás e para a frente, iluminando tanto a Antiguidade quanto a modernidade, ambas em constantes mudanças. 
O clássico seria, portanto, simultaneamente antigo e moderno (Martindale, 2013, p. 171, 175), sendo a interpretação dos textos greco-romanos (mas, também, de todo conteúdo clássico em sua enorme diversidade) indissociável da história de sua recepção. Para o autor, nenhuma obra tem seu significado integralmente determinado pela sua origem, daí a importância capital da recepção. Precisamos do passado para fazermos do presente algo novo, razão pela qual o passado importa tanto quanto o presente (Martindale, 2013, p. 181).

A ideia de recepção, longe do caráter de passividade que comumente lhe é atribuído, rejeita significados absolutos, definitivos, fundamentados em fontes originais decifradas e reproduzidas na posteridade. Ao criticar o caráter estático do clássico, as teorias da recepção apontam para o próprio processo histórico de construção das disciplinas que a ele se dedicam. A recepção, de forma passiva e acrítica, retira dos "receptores" o papel ativo e interativo que exercem diante do conhecimento advindo da Antiguidade, como se pudéssemos ler um autor antigo ou admirarmos uma obra de arte antiga retirando de nossas percepções tudo aquilo que nos constitui, em uma prática de consumo e adoção passiva daquilo que nos é dado, pronto, de antemão. Para Moses Finley,

Toda arte é um diálogo. Também o é todo o interesse pelo passado. E um dos lados, devido à sua própria existência vive e compreende de maneira contemporânea. Também parece ser inerente à existência humana que se torne e retorne ao passado [...]. Quanto mais cuidadosamente ouvimos, e quanto mais tomamos consciência do fato de ser passado, e até de sua quase-inacessibilidade, mais significativo se torna o diálogo. Ao final, só pode ser um diálogo no presente, sobre o presente. (Finley, 1991, p. 6-7)

Para Martindale, alguns autores creem na ideia de que recepção sugere um papel passivo para o leitor, preferindo o conceito de "apropriação", mas reitera que o uso de "recepção" envolve justamente o caráter dinâmico e dialógico da leitura (Martindale, 2007, p. 300), fazendo eco ao uso do conceito na Estética da recepção dos críticos alemães da Escola de Constança, cujas reflexões tornavam mais difícil cair em duas ilusões comuns nas interpretações literárias: o historicismo, que conduzia à ideia e ao desejo de conhecer o passado como realmente era, e o presentismo, que conduzia à ideia de que tudo está adaptado ao que pensamos no presente (Martindale, 2013, p. 171). Recepção, diferentemente de tradição ou herança, enfatiza o "papel ativo dos receptores" (Martindale, 2006, p. 11). 
Circundada por conceitos de tradição, herança, apropriação, usos e abusos do passado, e em relação com eles, recepção é um conceito de difícil definição. Nesta abordagem optamos por discutir as perspectivas anglo-saxãs em razão do impacto epistemológico que produziram na área da Antiguidade Clássica. Se recorrermos ao verbete "Recepção" do Oxford Classical Dictionary, escrito por Martindale e Lorna Hardwick, temos uma definição que aproxima o conceito de sua origem alemã, ligando-o à Escola de Constança, liderada por Hans Jauss e Wolfgang Iser, e frequentemente utilizado em substituição a palavras como tradição, herança e influência. A estrutura teórica proposta por Jauss e Iser, segundo os autores, funda-se na Hermenêutica de Gadamer tem por premissa que as interpretações sempre acontecem na história e estão sujeitas às contingências de seu momento histórico, não existindo uma leitura permanente e "correta" de um texto, mas uma "fusão de horizontes" em constante mudança entre texto e intérprete, enfatizando a importância do leitor no triângulo escritor-texto-leitor na produção de significado (Martindale; Hardwick, 2015). A recepção da Antiguidade Clássica, particularmente, pelo lugar que gregos e romanos ocupam na história do pensamento, não deixa de ser paradigmática para os estudos de recepção, em geral. Por transcender as fronteiras do mundo greco-romano, a recepção dos clássicos por muito tempo não foi entendida como parte dos estudos de História Antiga no Brasil, em contraste com sua inclusão no âmbito dos Classics na Europa e nos Estados Unidos. Postura essa, destacamos, que tem se alterado, e a presença de um artigo sobre recepção em um dossiê de História Antiga, em uma das principais revistas de História no Brasil, evidencia esse fato.

Ainda que entendamos os usos do passado como um campo da recepção e que pode em si ser objeto de estudos específicos, neste artigo voltamos nossos esforços para apresentar algumas linhas teóricas e situar o campo da recepção na historiografia sobre o mundo antigo produzida no Brasil, discutindo seu potencial epistemológico inovador e apresentando um estudo de caso, relacionado à recepção dos gregos antigos em Curitiba, na virada para o século XX.

\section{UM DOMÍNIO INCONTORNÁVEL: OS ESTUDOS SOBRE RECEPÇÃO}

Na introdução do livro Aspectos da Antiguidade, tomando o drama de Édipo Rei como exemplo, Finley estabelece uma questão crucial em relação à Antiguidade. A experiência dos antigos não nos é transmitida de modo direto; em relação a ela, somos como um estrangeiro, "lemos (ou vemos) Sófocles depois de termos lido (ou visto) Shakespeare, assim como admiramos a 
escultura grega arcaica com olhos e mentes que já viram Michelangelo e Henry Moore. A grande tradição é bidirecional" (Finley, 1991, p. 5) - daí sua defesa de um diálogo entre passado e presente (p. 6-7).

As teorias da recepção estimulam o diálogo apontado por Finley, pois "reconfiguraram" o entendimento tradicional do que são os clássicos, contestando sua natureza estática e evidenciável em seus próprios termos. Em Redeeming the Text: Latin Poetry and the Hermeneutics of Reception (Martindale, 1993), Martindale publicara o que pode ser entendido como um verdadeiro manifesto pela utilização da teoria da recepção nos Estudos Clássicos (Martindale, 2006, p. 1), proposta concebida como uma teoria de intervenção contra os denominados modos de pesquisa "positivistas" e em favor de como os textos clássicos podem ser mais proveitosamente interpretados (Martindale, 2013, p. 169), chamando a refletir sobre a construção dos significados. Martindale propusera que se voltasse para a intertextualidade das obras antigas, suas interpretações em contextos posteriores e a importância que exerceram sobre a literatura grega e romana.

Treze anos depois, em Classics and the Uses of Reception, livro co-organizado com Richard F. Thomas, aponta para uma expansão significativa do campo, exemplificando com sua inserção nos cursos de graduação e pós-graduação (particularmente no Reino Unido e nos Estados Unidos), com a decisão da Cambridge University Press, de meados dos anos 1990, de que seus Companions sobre autores antigos passassem a contemplar um elemento substancial de recepção, e com a inclusão do termo, em 2001, nas categorias de trabalho do campo dos Clássicos no Research Assessment Exercise, do Reino Unido (Martindale, 2006, p. 1).

É por essa razão que, no editorial do primeiro número do Classical Receptions Journal, Lorna Hardwick (2009) constata que o estudo da recepção de gregos e romanos tornou-se uma das áreas que mais crescem no campo dos Estudos Clássicos, ampliando domínios de investigação e estimulando o questionamento de estruturas explicativas e bases teóricas. A autora exemplifica apontando para o grande número de eventos e conferências que prestigiam a temática e para o crescente número de estudantes em diferentes níveis de formação que voltam seus interesses para esse campo, o que se faz acompanhar de uma presença cada vez mais frequente do tema nas grades curriculares das universidades, em centros de pesquisas e redes de colaboração nacional e internacional (Hardwick, 2009, p. 1-3). No universo editorial, a criação de uma série voltada para os estudos de recepção pela editora Brill - Brill's Companions to Classical Reception - também pode ser lida como um indício promissor da 
acolhida da recepção dos clássicos como campo de estudo, com títulos que abrangem temas ligados à arte, literatura, arquitetura, história, religião etc.

Em junho de 2013, por ocasião dos 20 anos da publicação da obra primordial de Martindale, o Classical Receptions Journal publicou um número especial, com contribuições de estudiosos que dialogaram com sua obra. Nessa mesma edição, além de tecer considerações às críticas que lhe foram feitas, Martindale apresentou um texto no qual propõe os estudos de recepção como nova forma de humanismo, na qual o caráter trans-histórico envolvido no aspecto dialógico de idas e vindas entre o presente e passado (Martindale, 2013, p. 173) seria uma parte da experiência humana necessária à interpretação dos grandes textos do passado; nele residiria a busca de comunalidades humanas muitas vezes fugidias ao longo da história, mas que surgiriam apenas nos processos de recepção. Em seu entendimento, em nossas interpretações não lidamos apenas com o "ontológico ou histórico", mas com ambos, e somente na recepção se poderia captar "esse movimento dialético", a implicação do histórico com o trans-histórico (Martindale, 2013, p. 179).

A Antiguidade, nessa perspectiva, muda constantemente o mundo em que vivemos, ao passo que esse mundo também muda a Antiguidade. A recepção de Virgílio, Horácio e Ovídio já na Antiguidade importa tanto quanto a desses autores no século XVIII, e de ambas as temporalidades nos séculos XIX e XX, em uma dinâmica constante de produção de significados, mas nenhum contexto histórico determina um único entendimento desses autores e de seus textos. A intertextualidade marca a relação da obra virgiliana com a de Homero, do mesmo modo que marca, também, a obra de autores como Lucano, Dante e Camões, e, mesmo, de tradutores como Odorico Mendes (Eneida Brasileira) com a de Virgílio, deixando em evidência as constantes relações entre fontes originais, sua recepção e a continuidade dessas recepções, mediadas pelas mais diferentes variáveis, sempre atuando na recriação dos clássicos, conferindo-lhes significados não apenas voltados para o passado, mas, também, para o presente e o futuro. As interpretações que fazemos dos clássicos estão inseridas em complexas trajetórias estabelecidas por uma "cadeia de recepções" (Martindale, 1993, p. 7) ininterruptas, carregadas de significados construídos ao longo do tempo, envolvendo o presente e o passado. Isto posto, passemos a explorar os diálogos entre passado e presente na historiografia sobre Antiguidade Clássica produzida no Brasil. 


\section{RELAÇÕES ENTRE PASSADO E PRESENTE NOS Estudos Sobre a ANTIguidade No Brasil}

A História Antiga universitária é tão tardia quanto a Universidade no Brasil (a USP surge em 1934), tendo como pioneiro Eurípedes Simões de Paula (1910-1977). Diversos aspectos estavam in nuce, já naqueles momentos iniciais, em particular como as relações sociais e de poder podiam conduzir a temas e abordagens originais para o passado antigo. Três aspectos inter-relacionados podem ser destacados: a mescla étnica e cultural; a exploração social (escravidão, servidão); a complexa relação intelectual de estudiosos periféricos com os centros acadêmicos hegemônicos.

A institucionalização da História Antiga, a partir dos anos 1930, coincidiu com a efervescência dos movimentos sociais e com as reflexões intelectuais sobre os três aspectos mencionados. A mescla étnica e cultural consistia um desafio, frente ao racialismo e racismo predominantes no cientificismo mais conservador, mas também uma oportunidade para os espíritos críticos. Frente à eugenia de um Renato Kehl $(1920 ; 1929 ; 1937)$ estavam apologistas da convivência, como Gilberto Freyre ([1933]1998), Caio Prado Júnior (1933), Sérgio Buarque de Holanda ([1936]1982) e Stefan Zweig (1941), críticos explícitos do racismo. Na então Faculdade de Filosofia, Ciências e Letras (FFCL) da Universidade de São Paulo atuavam intelectuais engajados na valorização da troca cultural, como Claude Lévi-Strauss, Fernand Braudel, Roger Bastide ou Pierre Monbeig. Autores como Fernando Ortiz (1906), José Carlos Mariátegui (1925) e Franz Boas (1914) eram lidos todos no sentido de enfatizar a diversidade étnica e cultural, assim como a mescla.

O segundo aspecto refere-se à exploração. Operários com muito trabalho e pouco lazer, trabalhadores do campo com ainda menos oportunidades, classes médias de limitadas possibilidades, greves, revoltas - esse contexto levava alguns a estarem atentos à exclusão social, derivada da escravidão, mas também a todo tipo de submissão social de caráter moderno, ou capitalista, das relações assalariadas. Para além dos intelectuais citados, outros, como Leôncio Basbaum ([1931]1976) e Afonso Schmidt (1942), ressaltavam como as formas de submissão são constitutivas do mundo e do Brasil (e vice-versa). Todos eram lidos e digeridos, no caldo de cultura da recém-criada disciplina acadêmica da História, e da História Antiga.

O terceiro aspecto é ainda mais ubíquo. Roberto Schwarz (1977) seguia

outros tantos (como Ariano Suassuna, 1957) e precedeu outros ainda (como Ferreira, 2008), na reflexão sobre a relação complexa, contraditória e essencial 
entre poderosos (as potências centrais) e periféricos (os outros todos), mas em particular no contexto de mescla cultural tão particular e profunda das Américas. Toda a reflexão sobre o modo de vida e a cultura passa pela relação ambígua, problemática, entre metrópole, no sentido amplo de dominante, e colônia/nação independente e dependente. Jorge Luis Borges ("La Biblioteca de Babel”, em Borges, 1944) atesta bem esses dilemas de estar no cerne do Ocidente, mas fora dele, ao mesmo tempo. Isso é tanto mais válido para a universidade, instituição infensa ao particularismo, dependente do poder econômico e político, cuja produção só se pode avaliar pelo êxito universal. Marx é lido dos centros hegemônicos originais (Europa, países ricos em geral) aos emergentes (China, Índia), aos marginais e excluídos (América Latina, África), tributário do grego Demócrito e do alemão Hegel, de modo que não se pode evitar o dilema da relação entre repertório (ocidental) e originalidade ou particularidade. Mao não pode ser entendido sem o grego e o alemão, mas talvez se possa ler Marx ou Foucault sem o chinês. Esse desafio é ainda mais profundo no Brasil e na vida acadêmica em particular.

Esses três aspectos estavam presentes já à época de Eurípedes Simões de Paula. O autor tratou, desde cedo, da mescla cultural, da exploração e da relação entre centro e periferia: O comércio Varegue e o Grão-Principado de Kiev (doutorado), Marrocos e suas relações com a Ibéria na Antiguidade (cátedra), orientação e organização de colóquios sobre temas como escravidão ou as corporações de ofício. Como administrador universitário, patrocinou o estudo da mescla, da exploração e das relações culturais, como atestam tanto as áreas desenvolvidas, como as pesquisas de professores e alunos. Chinês, árabe, hebraico, japonês, russo, história ibérica, pré-história e história da ciência estavam entre as áreas criadas. Os temas de pesquisa incluíam das relações entre a China e Roma na Antiguidade às culturas africanas.

Nesse contexto de longo prazo é possível entender os estudos que, de forma explícita, incluíram o presente, em particular brasileiro, no estudo da História Antiga. A Anistia (1979) e o retorno dos exilados, as eleições diretas para governador (1982), a chegada dos civis ao poder (1985) e a Constituição (1985) permitiram um novo florescimento do estudo da Antiguidade. A criação da Sociedade Brasileira de Estudos Clássicos (SBEC) (1985), as reuniões da Anpuh, as propostas curriculares estaduais (década de 1980), os diversos encontros de História, a publicação de paradidáticos, tudo contribuía para um aggiornamento da História Antiga. Se essa relação entre passado e presente existia desde o início, as restrições prevalecentes, em particular entre 1964 e 1979, dificultaram abordagens críticas. A partir daí, o ambiente favoreceu 
e mesmo estimulou a reflexão sobre a relação entre passado e presente, sobre o que se poderia chamar hoje de usos de passado. À época, tratava-se de estudar como a historiografia sobre a Antiguidade, em tempos posteriores, condicionou as percepções.

Mencionem-se ao menos três estudiosos que começaram a atuar nessa época, cuja produção sobre recepção ou usos do passado foi mais intensa nas décadas seguintes: José Antônio Dabdab Trabulsi (1998b; 2001; 2003; 2007; 2008; 2009; 2011a; 2011b; 2013), Francisco Murari Pires (2003; 2007; 2008; 2009; 2010a; 2010b; 2012; 2013) e Pedro Paulo A. Funari (Funari, 2015; 2018; 2019; Carlan et al., 2019; Funari; Garraffoni, 2018; Funari; Funari, 2015; Funari; Menezes, 2006; Funari; Poloni, 2017; Silva et al., 2017; Cavicchioli; Funari, 2011; Garraffoni; Funari, 2011). Na produção precoce de cada um desses autores, o presente brasileiro já estava, de alguma forma, expresso. Dabdab Trabulsi (1982) voltava-se para a crise social; Pires (1983) refletia sobre a reconstituição do passado, e Funari (1987) para o lugar da Antiguidade no currículo escolar. Ao longo de sua trajetória e em toda sua produção acadêmica, as preocupações teóricas estiveram presentes na obra desses historiadores.

Dabdab Trabulsi $(2009$, p. 9) já apontara para seu "interesse permanente pela historiografia moderna da Antiguidade e pelas representações do passado, em geral", debruçando-se sobre as interpretações contemporâneas do passado. Brasileiro, realizou sua formação de pós-graduação na Université de Besançon, sob orientação de Pierre Lévêque, o que marcaria de forma significativa sua produção acadêmica, levando-o a refletir, com base na história do mundo grego, sobre questões como a cidade e a democracia antigas e suas leituras modernas, sobre liberdade dos Antigos e dos Modernos, as relações entre a Revolução Francesa e o mundo clássico, enfim, sobre a permanência e as releituras da Antiguidade no universo intelectual e político francês, mas não só.

Já Pires, ao longo de sua trajetória, instigada por questões originariamente propostas pela obra de Tucídides, refletiu sobre "os pressupostos epistemológicos ativados pelo diálogo com que os Antigos são atualizados pelos Modernos no horizonte da tradição de pensamento acerca da Escrita da História no âmbito da civilização ocidental". Seu foco fora "os aportes do passado antigo na atualidade da reflexão moderna”, em proposta intelectual que configurava "intento divergente de reproposição que deslocasse a disciplina História Antiga - como tal institucionalmente regulamentada pelas normas regimentais disciplinadoras dos currículos dos cursos de História no país - por outra que tivesse por foco de proposição temática e reflexiva os diálogos entre Antigos e Modernos" (Pires, 2015, I). 
De formação acadêmica interdisciplinar, moldada nas trilhas da História, da Antropologia e da Arqueologia, a obra de Funari se caracteriza, em suas diferentes temáticas tratadas, pela importância conferida ao presente nas interpretações e explicações históricas, ao presente de historiadores, arqueólogos e estudiosos do passado, de modo geral, reservando singular importância à subjetividade e aos condicionamentos contemporâneos da interpretação do passado (2002, p. 15-23). No que concerne à história e à arqueologia do mundo antigo, a interface entre presente e passado em sua obra considerou temáticas ligadas ao estudo de subalternos e populares, à história política e militar, à história das mulheres e da sexualidade, da religião e da religiosidade, por exemplo, em frentes de abordagem que buscaram problematizar essas temáticas à luz dos nacionalismos, da crítica às ideias consolidadas de romanização, de questões de classe, raça e gênero, com uma crítica sempre presente aos modelos normativos de interpretação do passado.

Sob a orientação/supervisão desses formadores iniciais, pesquisas em diferentes níveis (iniciação científica, mestrado, doutorado e pós-doutorado) e com diferentes temáticas foram desenvolvidas no escopo epistemológico dos estudos de recepção e de usos do passado. Muitos doutores formados por esses pesquisadores orientaram e orientam, da iniciação científica ao doutorado, em similar perspectiva e abordagem (e também supervisionam pesquisas pós-doutorais). A abrangência temática dessas pesquisas, que evidenciam a relação direta do passado estudado com a dimensão coeva da produção historiográfica de diferentes momentos, aponta para a riqueza da pesquisa nacional nas frentes em questão, mas, também, para a sua conexão com uma das vertentes da historiografia sobre a Antiguidade mais promissoras no estrangeiro.

Ainda que o seu desenvolvimento se deva, sobretudo, aos influxos desses historiadores, os estudos sobre recepção e usos do passado no Brasil tiveram, no âmbito do Grupo de Trabalho em História Antiga (GTHA-Anpuh) e da SBEC, uma importante fonte de estímulo e desenvolvimento, ganhando fôlego num cenário historiográfico nacional inicialmente adverso aos seus pressupostos. Hoje, as pesquisas sobre tradições interpretativas e representações fundadas na Antiguidade (em diferentes domínios) expressam-se em uma miríade de trabalhos (monografias, dissertações, teses, artigos, livros e capítulos de livros), dando nomes a grupos de pesquisa, congressos, seminários e colóquios que se fazem valer de um duplo registro - antigo e moderno/contemporâneo, ilustrando a presença e a vitalidade dos estudos sobre recepção e usos do passado. 
Arrolar autores, obras, grupos e eventos transcende as expectativas deste texto, mas uma rápida consulta aos curricula dos professores de História Antiga listados na página do GTHA (http://www.gtantiga.com/) e aos associados da SBEC (https://www.classica.org.br/) permite perceber a dimensão hoje alcançada. É digno de nota que, nas edições bianuais do Simpósio Nacional de História (SNH), desde 2011 (10 anos após a realização de seu XXI encontro - A História no Novo Milênio: entre o individual e o coletivo - ocasião em que se reuniu pela primeira vez o GTHA), o grupo de pesquisa "Antiguidade e Modernidade: História Antiga e Usos do Passado” (dgp.cnpq.br/dgp/espelhogrupo/2318851719949896) tenha promovido a realização de cinco Simpósios Temáticos (intitulados "Antiguidade e Modernidade: usos do passado") com apresentações relacionadas aos estudos de recepção e usos do passado, congregando um total de 117 inscritos. ${ }^{2}$ A evidenciar a presença das temáticas em tela, além do grupo supracitado, cabe destacar a existência de outros grupos de pesquisa (História, Letras e Filosofia) registrados no Diretório de Grupos de pesquisa do CNPq. ${ }^{3}$

Esse contexto de diálogo e debate de ideias foi imprescindível para que a pesquisa sobre recepção em Curitiba se desenvolvesse. Conforme relatado em outra ocasião (Garraffoni, 2018), o interesse pelo tema foi despertado em interlocuções com essa rede de estudos sobre recepção que vem se organizando e se fortalecendo no país. O que surgiu como um encontro inesperado, em um estudo sobre a revista Joaquim, hoje se configura em grupo de pesquisa na Universidade Federal do Paraná (UFPR), envolvendo estudantes de graduação e pós-graduação, mas conectado com os debates nacionais e internacionais. Elegemos essa pesquisa como estudo de caso nesta ocasião por entendermos que ela só foi possível graças às discussões mencionadas na Anpuh e na SBEC, com seus espaços de debates para a consolidação de novos objetos de estudo.

\section{CURITIba dos Simbolistas, A EXPERIÊNCIA dos GREGOS ANTIGOS E A MODERNIDADE: UM ESTUDO DE CASO}

Além do fato de ser uma pesquisa que surgiu conectada com as discussões supracitadas, a razão dessa escolha como estudo de caso também está pautada em algumas premissas estratégicas, a saber: o deslocamento do eixo Rio-São Paulo, explorando como a Antiguidade Clássica se fez presente em uma cidade mais periférica no cenário político nacional na virada para o século XX; os poucos estudos existentes sobre a questão para essa região do país, e o fato de 
que, por alguns anos, poetas simbolistas decidiram criar espaços de cidadania e arte aos moldes da pólis ateniense, algo bastante particular e pouco conhecido no contexto da historiografia brasileira. Assim, ao focar no caso de Curitiba é possível explorar aquilo que Hardwick (2003, p. 4) já apontou nos estudos da recepção: sua potencialidade para pensarmos aspectos marginalizados tanto nas fontes antigas, como nas sociedades de sua recepção. É, portanto, ao mesmo tempo um estudo sobre recepção e sobre outras formas de entender a formação da identidade paranaense em geral e curitibana em específico.

Esse olhar para as complexas relações entre passado e presente implica construir uma metodologia particular - afinal, cada caso de recepção, embora tenha um substrato comum, a cultura grego-romana, apresenta particularidades e especificidades. No caso específico de Curitiba, o estudo só é possível pautado na interdisciplinaridade, um diálogo entre Literatura, História (Antiga e Contemporânea) e Arquitetura. Tal diálogo é imprescindível uma vez que foi do debate literário, político e artístico que surgiram muitos dos edifícios neoclássicos existentes até hoje na cidade, com destaque ao chamado "Prédio Histórico da Federal", edifício que abriga os cursos de Direito e Psicologia da UFPR, além de algumas de suas pró-reitorias - tombado como patrimônio e símbolo da cidade - e o Templo das Musas, para citar alguns dos exemplos mais conhecidos. Estamos, portanto, diante de um tema instigante, mas para apresentá-lo optamos por um recorte: as relações entre grupos literários e seus modos de vida na cidade na virada para o século XX e em suas primeiras décadas. Com essa perspectiva, exploraremos o contexto histórico da recepção e, também, defenderemos que os homens e mulheres que se inspiraram nos antigos gregos para construir seus ideais políticos e culturais não emularam as sociedades antigas nem as imitaram, ao contrário, criaram novos modos de vida (Garraffoni, 2018).

Para tanto, iniciamos com algumas considerações sobre o contexto da recepção. Em 1853 a província de São Paulo foi dividida e criou-se uma nova, a do Paraná. Bega (2013) afirma que, na época em que essa província foi criada, as plantations de erva-mate da região estavam em seu apogeu, o que gerou desdobramentos urbanos muito particulares em Curitiba: a elite política estava vinculada a uma produção agrária, mas o controle do produto final dependia da cidade, em especial da indústria nascente, responsável pela feitura dos recipientes para o armazenamento e transporte da erva, e da gráfica que imprimia os rótulos das embalagens para a venda do mate. Assim, ao final do século XIX, Curitiba se tornou a capital da província, passando a conhecer uma importante expansão das atividades da indústria da madeira, metalurgia e 
litografia. Essa particularidade foi fundamental para o avanço da produção cultural da cidade, já que muitas das gráficas começaram com a impressão de rótulos das embalagens para a divulgação do mate e, mais tarde, foram utilizadas para a produção de revistas literárias e jornais.

Bega argumenta que, com as políticas de imigração, a chegada em massa de alemães e franceses - experientes no trabalho em fábrica e na produção de seus próprios jornais operários - criou espaços de debates com a população local de origem portuguesa, africana e indígena. Assim, mesmo que Curitiba fosse considerada periférica em um plano nacional, diferenciou-se dos demais centros urbanos da região, pois se tornou um lugar bastante fértil para as atividades culturais e os embates intelectuais, criando um ambiente de debates intensos e confrontos ideológicos entre abolicionistas, anticlericalistas, anarquistas, socialistas e membros das elites mais conservadoras, defensoras dos valores burgueses e cristãos. É no bojo desses debates que uma nova geração de poetas começa a se destacar e, ao se juntarem com Cruz e Sousa, dão forma ao Movimento Simbolista. Dentre os nomes que nasceram ou viveram em Curitiba destacamos, como exemplo, Emiliano Pernetta, Dario Vellozo, Silveira Netto, João Itiberê da Cunha, Julio Pernetta e Euclides Bandeira.

Esses jovens se consideravam livres-pensadores e simbolistas e, além de suas atividades políticas e seus textos em jornais, dedicaram-se ao ocultismo e à gnose, chegando aos autores da Antiguidade por meio da Filosofia, em especial a grega. Em suas leituras do passado grego, as questões políticas e cotidianas eram muito importantes: debatiam conceitos como democracia, autonomia, isonomia, cidadania e vida urbana. Nesse sentido, por algumas décadas, entre o final do século XIX e os anos 1930, Curitiba experimentou um cotidiano cheio de musas gregas, poesia, debates políticos, competições desportivas ao estilo dos jogos olímpicos da Antiguidade. Pelo fato de o Simbolismo paranaense ter se misturado com o modo de vida grego, muitos estudiosos consideram o movimento peculiar ou exótico, e quando o mencionam, só o fazem brevemente, tanto nas antologias poéticas como na historiografia. No entanto, observando a abundante documentação, bem como a quantidade de pessoas nas fotos das festas por eles organizadas, defendemos que esses homens e mulheres misturaram os sistemas políticos gregos com seus conceitos de República e nação, criando um modo de vida coletivo próprio que, muitas vezes, entrou em choque com a identidade nacional que vinha sendo construída para o Brasil. Assim, o caso de Curitiba pode ser entendido como um exemplo da diversidade de formas com que a cultura clássica é recebida no Brasil e na 
América, permitindo uma discussão mais ampla sobre memória, identidade e modos de viver na cidade.

É possível encontrar nos arquivos do Museu Paranaense, da Biblioteca Publica ou da Casa da Memória uma documentação ampla e significativa, mas parcial, uma vez que boa parte do que havia no Templo das Musas - publicações, atas de reuniões, livros de biblioteca de Dario Vellozo - perdeu-se em um incêndio na década de 1980. Registar isso é importante, pois, sem dúvida, pelo que restou, fica evidente que o Simbolismo foi um marco na vida cultural, política e social da cidade, embora na historiografia se encontrem poucos estudos sobre o impacto das ideias de Baudelaire e seus desdobramentos no país. Há muito mais pesquisas sobre o Realismo e o Naturalismo no Rio de Janeiro, por exemplo, e o resultado disso é que se conhece muito mais sobre Machado de Assis do que sobre Cruz e Sousa e seus colegas simbolistas.

Cruz e Sousa nasceu em Santa Catarina e era amigo de Emiliano Pernetta, considerado por Bega (2013) o poeta que introduziu a leitura de Baudelaire entre os paranaenses. Pernetta, Vellozo e Cruz e Sousa, ao formarem uma rede de poesia em Curitiba, não só marcaram a cena cultural local e nacional como, por meio de Baudelaire, difundiram o ocultismo, a filosofia grega, a gnose e a crítica social. Embora haja muitos poetas no grupo Simbolista que, segundo Muricy (1952), causaram impacto profundo na literatura brasileira, para esta ocasião destacaremos apenas Dario Vellozo, pois já em seu tempo foi considerado o mais helenista de todos.

Vellozo nasceu no Rio de Janeiro em 26 de novembro de 1869, mas mudou-se com a família ainda muito jovem para Curitiba, onde faleceu em 28 de setembro de 1937. Desde a juventude dedicou-se à poesia e ao ensino: além de ter produzido escritos simbolistas - editou muitas revistas literárias, dentre as quais Cenáculo, Azul, Sapo, Mirto e Acácia, Esfinge, Ramo de Acácia, Pitágoras -, foi professor primário no Ginásio Paranaense (atual Colégio Estadual do Paraná), lecionando História Universal, português e filosofia. Sua trajetória inclui a fundação da Escola Brasil Cívico, o Instituto Neo-Pitagórico (INP) e a publicação de livros didáticos sobre História Antiga em geral e grega em particular. A Escola Brasil Cívico foi um projeto de poucos anos (1913-1914), já que foi concebida em Nova Krotona, uma colina em Rio Negro, povoado próximo a Curitiba, palco de conflitos na época da Guerra do Contestado. Como os combates foram violentos na região, o grupo de professores e estudantes voltou a Curitiba, onde seguiu seus estudos sobre filosofia grega e literatura no INP, fundado pouco depois e que ainda hoje existe e é ativo, tendo comemorado cem anos em $2018 .^{4}$ 
De maneira geral é possível afirmar que tanto a poesia de Vellozo como sua atividade como professor tinham os gregos antigos e a vida na pólis como referência. Em uma cidade na qual as decisões políticas importantes se davam em conjunto com as ações da Igreja católica, retomar a ideia de ação humana independente de um único deus e construir uma vida pública baseada nos princípios da ética democrática ajuda a explicar seus posicionamentos morais e políticos. Vellozo, seus seguidores e amigos tomaram do Simbolismo francês a gnose e o ocultismo e construíram uma forma própria de criticar a Igreja; além disso, quando se aproximaram da Filosofia Antiga criaram um tipo de sociabilidade helenística que levava em conta a ação coletiva contra os poderes políticos e religiosos locais. Assim, quando jovem, Vellozo e seu grupo, segundo Bega (2013), se definiam como livres pensadores e, por meio de sua forma de entender a vida na pólis, criaram um espaço político e cultural distinto de outras partes do país. Talvez o melhor exemplo para se entender o fenômeno seja a Festa da Primavera, em que musas gregas faziam-se presentes; as competições de música, poesia e esportes entre jovens criaram um espaço político de discussão sobre o que é a vida urbana, autonomia e igualdade, na época em que o estado do Paraná se formava.

A Festa da Primavera ocorreu de 1910 a 1913 e, além de contar com a organização de Vellozo e seus discípulos, recebia a presença do Grêmio das Violetas, o que expressa a presença ativa das mulheres nesses eventos. Ivan Santana (2015) destaca a produção de trajes gregos para os bailes no Club Curitibano, os cortejos com guirlandas, a eleição da Chloris - a rainha da Primavera -, os jogos olímpicos e poéticos. Além disso, Santana comenta que na primeira festa, de 1910, Emiliano Pernetta leu o poema "Sol" em homenagem a Dario Vellozo e, em 1911, antes do início da festa, Pernetta foi coroado Príncipe dos Poetas. A cerimônia, organizada por Vellozo, foi realizada no Passeio Público, e na ocasião construiu-se um templo grego de madeira onde Pernetta lançou uma edição especial do livro Ilusão e recebeu, de musas gregas, a coroa de louros que existe até hoje, sob guarda do Museu Paranaense. Após a Festa, Santana destaca que Pernetta vendeu, em 2 dias, quatrocentos exemplares de seu livro, fato noticiado em muitos jornais, inclusive na Gazeta de Notícias do Rio de Janeiro (Santana, 2015, p. 24). ${ }^{5}$

O que chama atenção nesses eventos é que os banquetes e celebrações ocorrem em conjunto com leituras de poemas e filosofia grega, produzindo ambiente propício para uma prática pedagógica coletiva, ou seja, criam-se outras formas de vida na cidade, construindo novas relações entre o indivíduo e a coletividade. Em 1911, já com os preceitos do INP funcionando nesses 
espaços públicos, antes da construção do Templo das Musas, Vellozo escreve uma carta a Emelino de Leão na qual explica: "O Neo pitagorismo não é seita, é Instituto; não impõe dogmas de especie alguma; oferece um método, um caminho, um regime físico, intelectual e moral, aproveitável ao indivíduo e à coletividade. Fica ao Indivíduo aproveitá-lo ou não, cumpri-lo ou rejeitá-lo" (Vellozo, 2009, p. 47).

Assim, todos os seus esforços, em conjunto com os de seus amigos poetas, foram na direção de construir espaços de autonomia política e intelectual e de estudo da cultura grega, criando uma fruição da experiência coletiva, marcando um lugar do novo estado do Paraná no universalismo ocidental. Concordamos com Willer (2010, p. 422) quando critica a forma como Vellozo e seus colegas simbolistas são descritos nos manuais de literatura brasileiros: quase sempre como irracionais ou exóticos por defenderem um modo de viver em diálogo com o passado grego. Willer defende a necessidade de novas abordagens, uma vez que a forma como Vellozo lia os antigos gregos e a criação do INP promoveram ações políticas muito particulares: foi anticlerical; abolicionista; defendeu em seus projetos educativos tanto a separação Igreja/Estado como a relevância de sua universalidade, ou seja, igualdade de educação para mulheres e homens; criticou severamente o extermínio da população indígena local; conhecia os preceitos anarquistas e socialistas. Mesmo que seja o mais ocultista e helenista do grupo, acreditamos que foi sincrético, procurou juntar seu presente com o passado grego, o Ocidente com o Oriente, em clara busca por uma síntese do conhecimento. Em um momento no qual a identidade da República ainda estava em construção, o passado grego e o presente de Curitiba se mesclaram em experiências políticas e sociabilidades únicas.

Se os eventos narrados são pouco conhecidos ou estudados na historiografia, cabe ressaltar que não é o mesmo que se observa no desenvolvimento da cena literária curitibana ao longo do século XX. Muricy ([1952]1980), que além de poeta é um grande compilador de poemas simbolistas e das influências do movimento, chamou atenção para o fato de que, já na década de 1950, o Romantismo foi definido como a vertente nacional, e o Simbolismo permaneceu como exótico e diletante, expondo as disputas estéticas e políticas no campo literário e dando exemplos concretos da fragilidade desses pressupostos. Dalton Trevisan, outro renomado escritor curitibano, foi ferrenho crítico da vertente Simbolista ao longo de sua vida; já Paulo Leminski, de certa forma, recuperou as utopias simbolistas em seus escritos. Ou seja, os debates na cena artístico-cultural de Curitiba acerca da presença greco-romana se iniciam com 
os Simbolistas no final do século XIX, atravessam o século XX e chegaram à contracultura.

Hara (2017) ao estudar a obra de Leminski afirma que sua admiração pelo Simbolismo o fez escrever a biografia de Cruz e Sousa, ao passo que Suzana Scramim (2010) já defendeu que é possível mapear as influências de Vellozo nos poemas de Leminski, em especial sua pulsão por criar novas experiências de vida. Nesse sentido, encerramos estas considerações sobre a relação entre os antigos e a literatura curitibana com Leminski, por uma razão simples: concretista, ligado aos movimentos contraculturais, mais de 50 anos depois, o poeta, boêmio como Emiliano Pernetta, frequentador do Templo das Musas, estudioso de grego e latim, tradutor do Satyricon de Petrônio, retomou os gregos e romanos e os reinseriu na cena poética, política e cotidiana curitibana. Traduziu o idioma antigo, escreveu em latim e grego, criticou a violência militar:

\section{de tortura militum \\ libera nos domine \\ de nocte infinita \\ libera nos domine \\ de morte nocturna \\ libera nos domine}

Paulo Leminski (em Flores, 2010, p. 108)

Flores (2010) destacou que esse poema, de fácil compreensão mesmo para aqueles que não dominam o latim, é intrigante na medida em que estabelece uma relação entre a prece e a busca pela liberdade. Leminski recorre ao latim subvertendo seu lugar religioso para criticar a repressão e buscar a liberdade em seu sentido mais radical. Ao que tudo indica é possível afirmar que o diálogo entre passado clássico e presente persiste na cena artística curitibana; se para alguns é diletante ou exótico, para outros é ferramenta para construção de novas identidades, de contestação, de busca pela fruição da vida e outras experiências coletivas possíveis. Entre a crítica, a utopia e a ação, gregos e romanos antigos teimam em seguir presentes em um lugar no qual nunca estiveram historicamente. Por essa razão, o estudo da relação entre Curitiba e os antigos nos desafia a compreender a polifonia greco-romana e a forma múltipla e dinâmica de sua recepção. 


\section{CONSIDERAÇÕES FINAIS}

Iniciamos nossa reflexão apresentando como os estudos sobre recepção em geral e usos do passado em específico constituem um campo rico e complexo. Buscamos analisar como, aos poucos, esse campo foi assumindo um papel atuante dentro dos Estudos Clássicos, em alguns casos alterando nossas percepções sobre a História Antiga. Pensar as relações entre passado e presente é o cerne destas reflexões e, por isso, elas flexibilizam as fronteiras espaço-temporais, criando objetos de estudos dinâmicos e surpreendentes, como a constituição do campo das artes e literatura em Curitiba.

Talvez o que tenha ficado implícito no texto, mas seria interessante ressaltar ao final, é que os estudos sobre recepção, no viés adotado, têm a linguagem como meio de sua constituição: ao propormos uma análise que considera discursos e linguagem, as fronteiras entre as disciplinas se reconfiguram, passado e presente se reordenam, instigando nossa sensibilidade a criar novos objetos. Essa seria a contribuição de Gadamer ressaltada por Martindale e Hardwick; a compreensão da fusão de horizontes entre passado e presente e a construção histórica e cultural da Antiguidade Clássica em outros momentos. Com este texto buscamos ressaltar como o estudo da recepção em ambientes acadêmicos abertos a debates (Anpuh e SBEC) permite não só a criação de novos objetos, mas, também, a rearticulação da maneira como historiadores ou historiadoras percebemos a fruição da vida no passado e no presente. $\mathrm{O}$ caso de Curitiba, nesse contexto, é exemplar: entre utopias e ações, entre gregos, romanos e paranaenses, viveu-se e vive-se. Trazer à tona e buscar compreender essa dinâmica é, para nós, um dos desafios mais instigantes que os estudos de recepção nos proporcionam.

\section{REFERÊNCIAS}

BASBAUM, Leôncio. História sincera da República: das origens até 1889. [1931]. São Paulo: Alfa-Ômega, 1976.

BEGA, Maria Tarcisa S. Letras e política no Paraná: simbolistas e anticlericais na República Velha. Curitiba: Ed. UFPR, 2013.

BOAS, Franz. Races, language and culture. New York: Macmillan, 1914.

BORGES, Jorge Luis. Ficciones. Buenos Aires: Sur, 1944.

HOLANDA, Sérgio B. de. Raízes do Brasil. [1936]. Rio de Janeiro: J. Olympio Ed., 1982.

CARLAN, Cláudio et al. (org.). As veias negras do Brasil: conexões brasileiras com a África. 2. ed. revisada. Ebook. Alfenas: Ed. Unifal, 2019. 
CAVICCHIOLI, Marina R.; FUNARI, Pedro Paulo A. Os usos do passado: considerações sobre o papel da Arqueologia na construção da identidade italiana. In: VIEIRA, Brunno; THAMOS, Márcio (org.). Permanência Clássica: usos contemporâneos da antiguidade greco-romana. São Paulo: Iluminuras, 2011. p. 111-124.

DABDAB TRABULSI, José Antonio. L'Antique et le Contemporain. Besançon: PUFC, 2009.

DABDAB TRABULSI, José Antonio. La cité grecque positiviste: anatomie d'un modèle historiographique. Paris: L'Harmattan, 2001.

DABDAB TRABULSI, José Antonio. Le 'clientélisme public' de Périclès dans l'historiographie du XX siècle. In: GALLEGO, Julián et al. (org.). Rapports de subordination personnelle et pouvoir politique dans la Méditerrannée antique et au-délà. Besançon: PUFC, 2013. p. 127-139.

DABDAB TRABULSI, José Antonio. Gibbon. In: LOPES, Marco Antonio (org.). Ideias de História: tradição e inovação de Maquiavel a Herder. Londrina: Eduel, 2007. p. 253-302.

DABDAB TRABULSI, José Antonio. Liberdade, Igualdade, Antiguidade: a Revolução Francesa e o Mundo Clássico. Phoinix, Rio de Janeiro, v. 4, p. 205-255, 1998a.

DABDAB TRABULSI, José Antonio. Liberté des Anciens et des Modernes: une critique de la lecture libérale. In: GARRIDO-HORY, Margueritte (org.). Histoire, Espaces et Marges de L'Antiquité. Besançon: PUFC; Paris: Belles Lettres, 2003. p. 47-64.

DABDAB TRABULSI, José Antonio. Um Péricles ianque. In: HIRATA, Elaine (org.). Estudos sobre o Espaço na Antiguidade. São Paulo: Edusp, 2011b. p. 15-40.

DABDAB TRABULSI, José Antonio. Le Present dans le Passé. Besançon: PUFC, 2011 a.

DABDAB TRABULSI, José Antonio. Religion et société en Grèce ancienne: crise sociale, tyrannie et diffusion du dionysisme à l'époque archaïque. 1982. Dissertação (Mestrado em História) - Université de Besançon. Besançon, 1982.

DABDAB TRABULSI, José Antonio. Religion grecque et politique française au XIXe siècle. Paris: L'Harmattan, 1998b.

DABDAB TRABULSI, José Antonio. Tradição Clássica, ensino e política na França da Terceira República. In: CHEVITARESE, André et al. (org.). A tradição clássica e o Brasil. Brasília: Fortium: Archai, 2008. p. 123-141.

FERREIRA, Lúcio M. Patrimônio, Pós-Colonialismo e Repatriação Arqueológica. Ponta de Lança (UFS), v. I, p. 37-62, 2008.

FINLEY, Moses. Aspectos da Antiguidade. Tradução de Marcelo Brandão Cipolla. São Paulo: Martins Fontes, 1991.

FINLEY, Moses. The Use and Abuse of History. London: Chatto \& Windus, 1975.

FLEMING, Katie.The Politics and Morality of Appropriation. In: MARTINDALE, Charles; THOMAS, Richard F. (ed.). Classics and the Uses of Reception. Oxford: Blackwell Publishing, 2006. p. 127-138. 
FLORES, Guilherme Gontijo. O raro do reles: um latim de bandido. In: SANDMANN, Marcelo (org.). A pau a pedra a fogo a pique: dez estudos sobre a obra de Paulo Leminski. Curitiba: Secretaria da Cultura, 2010. p. 102-139.

FREYRE, Gilberto. Casa-grande e senzala: formação da família brasileira sob o regime da economia patriarcal. [1933]. 34. ed. Rio de Janeiro: Record, 1998.

FUNARI, Pedro Paulo A. Antiguidade clássica: a história e a cultura a partir dos documentos. Campinas: Ed. Unicamp, 2002.

FUNARI, Pedro Paulo A. Antiguidade, proposta curricular e formação de uma cidadania democrática. Revista Brasileira de História, São Paulo: Anpuh, v. 7, n. 14, p. 261-262, 1987.

FUNARI, Pedro Paulo A. Objetividade e subjetividade na historiografia. Heródoto, v. 3, n. 1, p. 600-609, 2018.

FUNARI, Pedro Paulo A. Péricles de Atenas. Revista Mundo Antigo, Rio de Janeiro, v. 6, p. 155-158, 2015.

FUNARI, Pedro Paulo A. Prefácio: Agostinho de Hipona, da Antiguidade à Atualidade. In: BORGES, André; MELO, José Joaquim P. (org.). Agostinho em Diálogo, Filosofia, Teologia, História, Educação. São Paulo: Fonte, 2019. p. 9-14.

FUNARI, Pedro Paulo A.; FUNARI, Raquel dos S. O presente do passado: o Egito no Brasil. Hélade, Rio de Janeiro, v. 1, p. 35-43, 2015.

FUNARI, Pedro Paulo A.; GARRAFFONI, Renata S. Sallust, Between Past and Present. Scripta Antiqua, v. 109, p. 126-137, 2018.

FUNARI, Pedro Paulo A.; MENEZES, Lúcio. A Social History of Brazilian Archaeology: A Case Study. Bulletin of the History of Archaeology, v. 16, p. 18-27, 2006.

FUNARI, Pedro Paulo A.; POLONI, Juliana. Nacionalismo e ciência: Arqueologia, imperialismo e Estado Novo em contexto luso-brasileiro. In: COSTA, Cléria B. da; RIBEIRO, Maria do E. S. R. C. (org.). Fronteiras móveis: territorialidades, migrações. Belo Horizonte: Fino Traço, 2017. p. 283-300.

GARRAFFONI, Renata S. Os Antigos Gregos no acervo do Museu Paranaense: recepção dos clássicos, poesia simbolista e política. Curitiba: Samp, 2018.

GARRAFFONI, Renata S.; FUNARI, Pedro Paulo A. Antiguidade e Modernidade: considerações sobre os usos do passado. In: SIMPÓSIO NACIONAL DE HISTÓRIA, 26., 2011, São Paulo. Anais... São Paulo: USP, 2011. p. 1-10.

GEARY, Patrick J. O Mito das Nações: a invenção do nacionalismo. Tradução de Herbert Balmann. Lisboa: Gradiva, 2008.

GOMES, Oscar. A sagração do poeta. Curitiba: Fanal, 1911.

HARA, Toni. Saber Noturno: uma antologia de vidas errantes. Campinas: Ed. Unicamp, 2017.

HARDWICK, Lorna. Editorial. Classical Receptions Journal, v. 1, n. 9, p. 1-31, 2009. HARDWICK, Lorna. Reception Studies. Oxford: Oxford University Press, 2003. 
HARDWICK, Lorna; STRAY, Christopher. A Companion to Classical Receptions. Oxford: Blackwell, 2008.

HARTOG, François. Anciens, modernes, sauvages. Paris: Galaade, 2005.

HARTOG, François; REVEL, Jacques. Note de conjoncture historiographique. In: HARTOG, François; REVEL, Jacques (org.). Les usages politiques du passé. Paris: Éd. de l'EHESS, 2001.

HINGLEY, Richard (ed.). Images of Rome: Perceptions of Ancient Rome in Europe and the United States of America in the Modern Age. Journal of Roman Archaeo$\log y$, Supplementary Series, v. 44, 2001.

KARLSSON, Klas-Göran. Processing Time: On the Manifestations and Activations of Historical Consciousness. In: BJERG, Helle et al. (ed.). Historicizing the Uses of the Past: Scandinavian Perspectives on History Culture, Historical Consciousness and Didactics of History Related to World War II. Bielefeld: Transcript Verlag, 2011. p. 129-145.

KEHL, Renato. Eugenia e medicina social. Rio de Janeiro: Livr. Francisco Alves, 1920. KEHL, Renato. Lições de eugenia. Rio de Janeiro: Livr. Francisco Alves, 1929.

KEHL, Renato. Por que sou eugenista? 30 anos de campanha eugênica. Rio de Janeiro: Livr. Francisco Alves, 1937.

MARIÁTEGUI, José Carlos. La escena contemporânea. Lima: Ed. Minerva, 1925.

MARTINDALE, Charles. Reception. In: KALLENDORF, Craig W. (ed.). A Companion to the Classical Tradition. Oxford: Blackwell Publishing, 2007. p. 297-311.

MARTINDALE, Charles. Reception - a new humanism? Receptivity, pedagogy, the transhistorical. Classical Receptions Journal, v. 5, n. 2, p. 169-183, 2013.

MARTINDALE, Charles. Redeeming the Text: Latin Poetry and the Hermeneutics of Reception. Cambridge: Cambridge University Press, 1993.

MARTINDALE, Charles. Thinking Through Reception: Introduction. In: MARTINDALE, Charles; THOMAS, Richard (ed.). Classics and the Uses of Reception. Malden: Blackwell Publishing, 2006. p. 1-13.

MARTINDALE, Charles; HARDWICK, Lorna. Reception. In: The Oxford Classical Dictionary. Oxford: Oxford University Press, 2015. Disponível em: https://oxfordre.com/classics/view/10.1093/acrefore/9780199381135.001.0001/acrefore-9780199381135-e-5507?rskey=Zl7s5H\&result=1. Acesso em: 3 fev. 2020.

MOMIGLIANO, Arnaldo. The Classical Foundations of Modern Historiography. Berkeley, CA: University of California Press, 1990.

MURICY, Andrade. Panorama do Movimento Simbolista Brasileiro. [1952]. São Paulo: Perspectiva, 1980.

ORTIZ, Fernando. Los negros brujos (apuntes para un estudio de etnología criminal). Madrid: Librería de Fernando Fe, 1906.

PIRES, Francisco M. Antigos e modernos, o fardo e o fio. Revista de História, São Paulo: USP, n. especial, p. 9-18, 2010a.

PIRES, Francisco M. O Fardo e o Fio: na contramão da procissão historiográfica. (Intrigas Tucidideanas acerca da escrita da História). São Paulo: Armazém Digital, 2015. Disponível em: https://www.academia.edu/18708132/O_Fardo_e_o_Fio_na_ 
contram\%C3\%A3o_da_prociss\%C3\%A3o_historiogr\%C3\%A1fica_Intrigas_Tucidideanas_acerca_da_Escrita_da_Hist\%C3\%B3ria. Acesso em: 3 fev. 2020.

PIRES, Francisco M. O General Marshall em Princeton, Tucídides na Guerra Fria. História da Historiografia, Mariana, v. 2, p. 101-115, 2009.

PIRES, Francisco M. Indagações sobre um método acima de qualquer suspeita. História da Historiografia, Mariana: Ufop, v. 13, p. 24, 2013.

PIRES, Francisco M. Leonardo Bruni e Tucídides: história e retórica. Politéia, Vitória da Conquista, v. 6, n. 1, p. 57-84, 2007.

PIRES, Francisco M. Machiavel et Thucydide: le(s) regard(s) de l'histoire et les figurations de l'historien. Cahiers des Etudes Anciennes, v. 47, p. 263-281, $2010 \mathrm{~b}$.

PIRES, Francisco M. Machiavel, la cour des Antiques et (le dialogue avec) Thucydide. Dialogues d'Histoire Ancienne, Besançon, v. 34, n. 1, p. 59-84, 2008.

PIRES, Francisco M. Percepçães da Atenas ancestral: comprometimento e moderação na reconstituição do passado. 1983. Tese (Doutorado em História) - FFCL, Universidade de São Paulo. São Paulo, 1983.

PIRES, Francisco M. O Porto de Pilos e a baía de Navarino, Tucídides e o coronel Leake: akríbeia antiga mais crítica moderna e as temporalidades da história tucidideana. Phaos, Campinas, n. 3, p. 95-114, 2003.

PIRES, Francisco M. Ranke e Nieburh: a apoteose tucidideana. Revista de Historia, São Paulo: USP, v. 116, p. 71-108, 2012.

PRADO JÚNIOR, Caio. Evolução Política do Brasil. São Paulo: Brasiliense, 1933.

SANTANA, Ivan J. Emiliano Perneta: vida e poesia de província? 2015. Tese (Doutorado em Letras) - Universidade Federal do Paraná. Curitiba, 2015.

SCHMIDT, Afonso. Colônia Cecília, uma aventura anarquista na América, 1889 a 1893. São Paulo: Anchieta, 1942.

SCHWARZ, Roberto. Ao vencedor as batatas. São Paulo: Duas Cidades, 1977.

SCRAMIM, Suzana. Paulo Leminski e o simbolismo. In: SANDMANN, Marcelo (org.). A pau a pedra a fogo a pique: dez estudos sobre a obra de Paulo Leminski. Curitiba: Secretaria da Cultura, 2010. p. 216-243.

SILVA, Glaydson José da. História Antiga e usos doa passado: um estudo de apropriações da Antiguidade sob o Regime de Vichy. São Paulo: Annablume, 2007.

SILVA, Glaydson José da. Historicidade, memória e escrita da História. Augusto e o 'culto della romanità' durante o ventennio fascista. Romanitas - Revista de Estudos Grecolatinos, n. 12, p. 142-163, 2018.

SILVA, Glaydson José da et al. (org.). Antiguidade como Presença: antigos, modernos e os usos do passado. Curitiba: Prismas, 2017.

SUASSUNA, Ariano. Auto da compadecida. [1955]. Rio de Janeiro: Agir, 1957.

VELLOZO, Dario. Escola Brasil Cívico - coletânea organizada pelo Instituto Neo-Pitagórico. Curitiba: INP, 2009.

VEYNE, Paul. L'Émpire Gréco-Romain. Paris: Éd. du Seuil, 2005.

WILLER, Claudio. Um obscuro encanto: gnose, gnosticismo e poesia moderna. Rio de Janeiro: Civilização Brasileira, 2010.

ZWEIG, Stefan. Brasil, país do futuro. Rio de Janeiro: Ed. Guanabara, 1941. 


\section{NOTAS}

${ }^{1}$ A recepção nos Estudos Clássicos comumente se refere àquilo que Charles Martindale denominou de "material pós-clássico" (MARTINDALE, 2006); entendemos, contudo, que a mobilização do conceito permite compreender, já na Antiguidade, diferentes tipos de relações - a recepção de Homero, por exemplo, entre gregos que lhe foram posteriores.

${ }^{2}$ Muitos participantes se inscreveram em mais de uma edição. Informações disponíveis em:

XXVI SNH - ANPUH 50 anos (São Paulo) - 31 inscritos (http://www.snh2011.anpuh. org/simposio/programacao?ID_SIMPOSIO=504)

XXVII SNH - Conhecimento histórico e diálogo social (Natal) - 10 inscritos

(http://www.snh2013.anpuh.org/simposio/view?ID_SIMPOSIO=1155)

XXVIII SNH - Lugares dos historiadores: velhos e novos desafios (Florianópolis) - 21

inscritos;

(http://www.snh2015.anpuh.org/simposio/view?ID_SIMPOSIO=2021)

XXIX SNH - Contra os preconceitos: história e democracia (Brasília) - 30 inscritos

(http://www.snh2017.anpuh.org/simposio/view?ID_SIMPOSIO=94)

XXX SNH - História e o futuro da educação no Brasil (Recife) 25 inscritos

(https://www.snh2019.anpuh.org/simposio/view?ID_SIMPOSIO=186)

3 "Antiguidade e Contemporaneidade em perspectiva: Espaços, Identidades e Hibridismos" (História/UFF); "História Antiga e Usos do Passado: novas perspectivas entre o passado e o presente" (História/UFMS); "PROAERA - Programa de Estudos em Representações da Antiguidade" (Letras/UFRJ); "Antigos e Modernos: questões contemporâneas" (Filosofia/Unila); "LINCEU - Visões da Antiguidade Clássica" (Letras/Unesp-Araraquara); "Grupo de Pesquisa Historiografia do Mundo Antigo" (História/Uesb); "Grupo de Estudos em Residualidade Antigo-Medieval” (História/UVA-CE).

${ }^{4}$ Há uma publicação do INP com os documentos da Escola Brasil Civico que reúne notícias de jornais e cartas das pessoas sobre suas experiências na escola, entre outros. Esse tipo de publicação é interessante na medida em que reúne o que sobrou da documentação sobre a Escola, pois, como mencionado, muita coisa se perdeu no incêndio (VELLOZO, 2009).

${ }^{5}$ Para uma descrição completa da coroação, ver Gomes, 1911.

Artigo recebido em 7 de fevereiro de 2020.

Aprovado em 25 de maio de 2020.

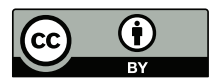

